\title{
ON THE VARIABILITY OF SIMULATED SOURCE-RECEPTOR RELATIONSHIPS FOR SULFUR DEPOSITION
}

\author{
Perry J. Samson, Mark Fernau, and Patricia Allison \\ Department of Atmospheric and Oceanic Science \\ University of Michigan \\ Ann Arbor, Michigan 48109-2143
}

\begin{abstract}
The use of Lagrangian models to estimate source-receptor relationships for ambient $\mathrm{SO}_{4}{ }^{-}$concentrations and $S$ deposition has become fairly widespread over the past several years. This paper addresses the sensitivity of long-term simulations of a Lagrangian $S$ transport and deposition model to actual variations in $\mathrm{SO}_{2}$ emissions and meteorological conditions. The variations of predicted source-receptor relationships due to (1) the inclusion of day to day variations in emissions strength as opposed to the use of the annual average daily emission rate and (2) year-to-year variations in meteorological conditions were studied to identify causes of uncertainty in a Lagrangian model. The results suggested that adding information on day to day emission variations for a specific point source resulted in variations in estimated $S$ wet deposition of the order of only $20 \%$ within $500 \mathrm{~km}$ of the source. Year-to-year variations in meteorological conditions, on the other hand, resulted in variations in predicted $S$ wet deposition of the order of $50 \%$ for some receptors. The variation in estimated source-receptor relationships for a given source/receptor combination was found to range as high as 70 \% over a 5-yr modeling period.
\end{abstract}

\section{INTRODUCTION}

The impact of sulfur dioxide and nitrogen oxide emissions on air and precipitation quality at receptors located hundreds of kilometers downwind of a source is still poorly understood. Several atmospheric transport and deposition models have been used to estimate these impacts but the modeling has been plagued with problems of uncertainty in both model formulation and in the necessary input data for emissions strengths and meteorology. Because the results of these models have been and will be used to aid in the design of costly emission control strategies it is important that we examine possible sources of uncertainty due both to input data quality and expected fluctuations of meteorological conditions. This paper examines the sensitivity of Lagrangian model simulations of airborne sulfate $\left(\mathrm{SO}_{4}{ }^{2}\right)$ concentrations 
and wet sulfur (S) deposition to the use of seasonal, monthly and daily averaged emissions information instead of annually averaged emissions information. Additionally, the magnitude of expected variations in annual averaged ambient $\mathrm{SO}_{4}=$ concentrations and annual total $S$ wet deposition due to year-to-year variations in meteorological conditions in eastern North America are estimated. Finally, the sensitivity of simulated source-receptor relationships to year-to-year variations in meteorological conditions are also explored.

The first part of this paper examines how much uncertainty in modeled estimates of source-receptor relationships results from ignoring temporal variations in sulfur dioxide $\left(\mathrm{SO}_{2}\right)$ emission rates. On a regional scale most modeling efforts have concentrated on representing meteorological variations accurately but have ignored temporal oscillations in $\mathrm{SO}_{2}$ emission rates by using annually or, at best, seasonally averaged emissions to examine source-receptor relationships. Using daily emissions data from an electric generating facility located in southeastern Michigan, the relative effect of using emissions data representative of four different averaging periods was examined.

The second part of this paper illustrates the year-to-year changes expected in annual average $\mathrm{SO}_{4}{ }^{=}$concentration and total annual $S$ wet deposition at several locations in eastern North America due to changing meteorological conditions. This analysis was necessary to evaluate the natural "noise" upon which the signal of changing emissions impact will need to be discerned. In addition, variations in predicted source-receptor relationships were noted to assess the feasibility of being able to identify meaningful signals from targeted emission control scenarios.

The results of the model exercises are expressed as either the natural potential (also referred to as the "normalized source-receptor matrix elements") for contribution to a receptor or as an estimate of the absolute contribution to a receptor. The natural potential for contribution represents estimates of the probability of $S$ emitted at a given location impacting a given receptor as $\mathrm{SO}_{2}, \mathrm{SO}_{4}{ }^{\prime}, S$ dry or $s$ wet deposition due to the existing meteorological conditions and assumed chemical transformation and scavenging without regard to actual emission densities. The absolute contribution is the linear product of the natural potential field and the actual emissions density.

\section{METHODS}

The University of Michigan Atmospheric Contributions to Interregional Deposition (ACID) model calculates short-term (daily) $\mathrm{SO}_{2}$ and $\mathrm{SO}_{4}=$ concentrations and $S$ deposition due to regional-scale transport. Details of the model are presented elsewhere (Samson and Small, 1982). The ACID Model can be used in either of two modes. To investigate variations in downwind deposition patterns associated with varying emission averaging, the forward mode was used. To investigate changes in deposition at specific receptors due to the changes in meteorological conditions, the backward mode was used. 
In order to estimate the transport path of the air leaving a source in the forward mode or arriving at a receptor in the backward mode trajectories have been calculated based on observed upper-air winds. A trajectory represents the center-of-mass of probability for air to be transported from a source to a receptor. The probability of a reactive tracer wet depositing at a point $x$ at a time $t, w_{s}(x, t)$, can be expressed as

$$
\begin{aligned}
& W_{s}(x, t)=\varepsilon_{s}(x, t) \int_{t-\tau}^{t} \int_{-\infty}^{\infty} \int_{-\infty}^{\infty} Q\left(x, t \mid x^{\prime}, t^{\prime}\right) R\left(t \mid t^{\prime}\right) \times \\
& \quad \times D_{s}\left(x^{\prime}, t^{\prime}\right) \Lambda\left(x^{\prime}, t^{\prime}\right) d x^{\prime} d t^{\prime}
\end{aligned}
$$

where $\varepsilon_{s}(\boldsymbol{x}, t)$ is the fractional efficiency of wet deposition of the tracer at point $(\boldsymbol{x}, t) . Q\left(\boldsymbol{x}, t \mid \boldsymbol{x}^{\prime}, t^{\prime}\right)$ is the probability of an air parcel located at $\boldsymbol{x}^{\prime}$ at time $t^{\prime}$ arriving at a receptor $\boldsymbol{x}$ at time $t$, $R\left(t \mid t^{\prime}\right)$ is the probability of the tracer not being chemically transformed to another species from time $t^{\prime}$ to time $t, D_{s}\left(\boldsymbol{x}^{\prime}, t^{\prime}\right)$ is the probability that the tracer will not be dry deposited at $\left(x^{\prime}, t^{\prime}\right)$ and $\Lambda\left(\mathbf{x}^{\prime}, t^{\prime}\right) \quad\left(=1-\varepsilon_{\mathrm{s}}\left(\mathbf{x}^{\prime}, t^{\prime}\right)\right)$ is the probability that the tracer will not be wet deposited at $\left(\boldsymbol{x}^{\prime}, t^{\prime}\right)$. The integration is continued over a period $\tau$ which has been prescribed in this study as $72 \mathrm{hr}$ (or less if the trajectory calculation terminated prematurely due to missing input data).

The product of the last three probability functions can be approximated for $S$ by solving the coupled equations

$$
\begin{aligned}
& \mathrm{d} s / \mathrm{d} t=-\mathrm{k}_{\mathrm{t}} s-\mathrm{k}_{\mathrm{d}} s-\mathrm{k}_{\mathrm{w}} s+\mathrm{E}_{s} \\
& \mathrm{~d} p / \mathrm{dt}=+\mathrm{k}_{\mathrm{t}} s-\mathrm{k}_{\mathrm{d}} p-\mathrm{k}_{\mathrm{w}} p+\mathrm{E}_{p}
\end{aligned}
$$

where $s$ is the probability of $S$ occurring as $\mathrm{SO}_{2}, p$ is the probability of $S$ occurring as $\mathrm{SO}_{4}{ }^{-}, \mathrm{k}_{\mathrm{t}}$ is the linear rate of transformation of $S$ from $\mathrm{SO}_{2}$ to $\mathrm{SO}_{4}{ }^{-}, k_{d}$ and $\mathrm{k}_{\mathrm{w}}$ are the rates of dry and wet deposition, respectively, for $\mathrm{SO}_{2}$, and $\kappa_{d}$ and $\kappa_{w}$ are the rates of dry and wet removal, respectively, for $\mathrm{SO}_{4}=$. Some fraction, $\mathrm{E}_{p^{\prime}}$ (usually thought to be about $1 \%$ to $5 \%$ ) of the initial probability of emitted $S$ is assumed to be $\mathrm{SO}_{4}=$ while the majority of the initial probability is assumed to be $\mathrm{SO}_{2}$. The chemical transformation rate, $\mathrm{k}_{\mathrm{t}}$ and the $\mathrm{SO}_{2}$ and $\mathrm{SO}_{4}=\mathrm{dry}$ deposition rates are presumed to vary diurnally and seasonally. The wet deposition rates are assumed to be dependent upon precipitation rate following scott (1982).

To test the sensitivity of simulated concentrations and deposition to emissions averaging the $\mathrm{SO}_{2}$ emissions input data were varied to reflect daily, monthly, seasonally and annually averaged emissions for one source. All averaging periods longer than a day were derived from ensembles of daily emissions data. Seasons were defined as 3 month 
periods, beginning January, April, July and October. Model runs were made for all averaging times for each year from 1976 to 1981, except 1979, for which a complete year's worth of emissions data were not available. The model output included estimates of daily ambient $\mathrm{SO}_{2}$ and $\mathrm{SO}_{4}=$ concentrations and daily total $S$ dry and wet depositions in each cell of the $45 \times 36$ grid, ranging from $25^{\circ} 30^{\prime} \mathrm{N}$ to $51^{\circ} 21^{\prime} \mathrm{N}$ and from $60^{\circ} 88^{\prime} \mathrm{W}$ to $104^{\circ} 88^{\prime} \mathrm{W}$. This grid dimensions were $1^{\circ}$ longitude by $0.74^{\circ}$ latitude (equal to the $1^{\circ}$ longitude at the latitude of Ann Arbor, Michigan). Hence the area of the grid cells varied from the north $\left(\approx 5700 \mathrm{~km}^{2}\right)$ to the south $\left(\approx 8300 \mathrm{~km}^{2}\right)$. The model was run in the forward mode using four downwind (forward) trajectories per day.

To simulate the variations in concentrations, deposition and source-receptor relationships due to year-to-year variations in meteorological conditions the backward mode used four upwind (backward) trajectories per day to calculate the natural potential for contribution to $\mathrm{SO}_{4}=$ concentrations and $s$ wet deposition at specific receptors. The potential was then multiplied by the emissions in each cell to estimate source contribution. In this study the potential was calculated for six years (1976 to 1981) and multiplied by an emissions inventory compiled for 1980. The model output includes estimates of contributions to daily ambient $\mathrm{SO}_{2}$ and $\mathrm{SO}_{4}{ }^{2}$ concentrations and daily total $S$ dry and wet depositions from each cell.

These estimates were integrated over the area of states and provinces to investigate modeled fluctuations in source-receptor relationships over the period.

\section{INPUT DATA}

\subsection{Emissions Data}

The emissions level for an electric generating facility varies from day to day in response to changing load demands, maintenance requirements and economic factors. Thus a wide distribution of daily emission strengths is possible. This variation in emission rates could, presumably, affect the estimation of annual impact on air and precipitation quality downwind of the facility in contrast to similar estimates made using only an annual averaged daily emission rate. In order to estimate the degree of variation in modeled deposition patterns incurred by ignoring day to day variations in emissions, the daily $\mathrm{SO}_{2}$ emissions were obtained from one point source for five years: 1976, 1977, 1978, 1980, and 1981. Frequency distributions of daily emission rates normalized by the mean emission rate the whole period are shown in Figure 1 . The figure shows that there was a wider distribution of emission rates in the earlier years studied than in later years. The greatest range in emissions occurred in 1977. The greatest standard deviation of daily emissions occurred in 1976 reflecting fluctuations in operating conditions during the source's first year of operation. In 1980 and 1981, there was a significant decrease in the peak emission and in the variation of the emissions from the year's mean. 


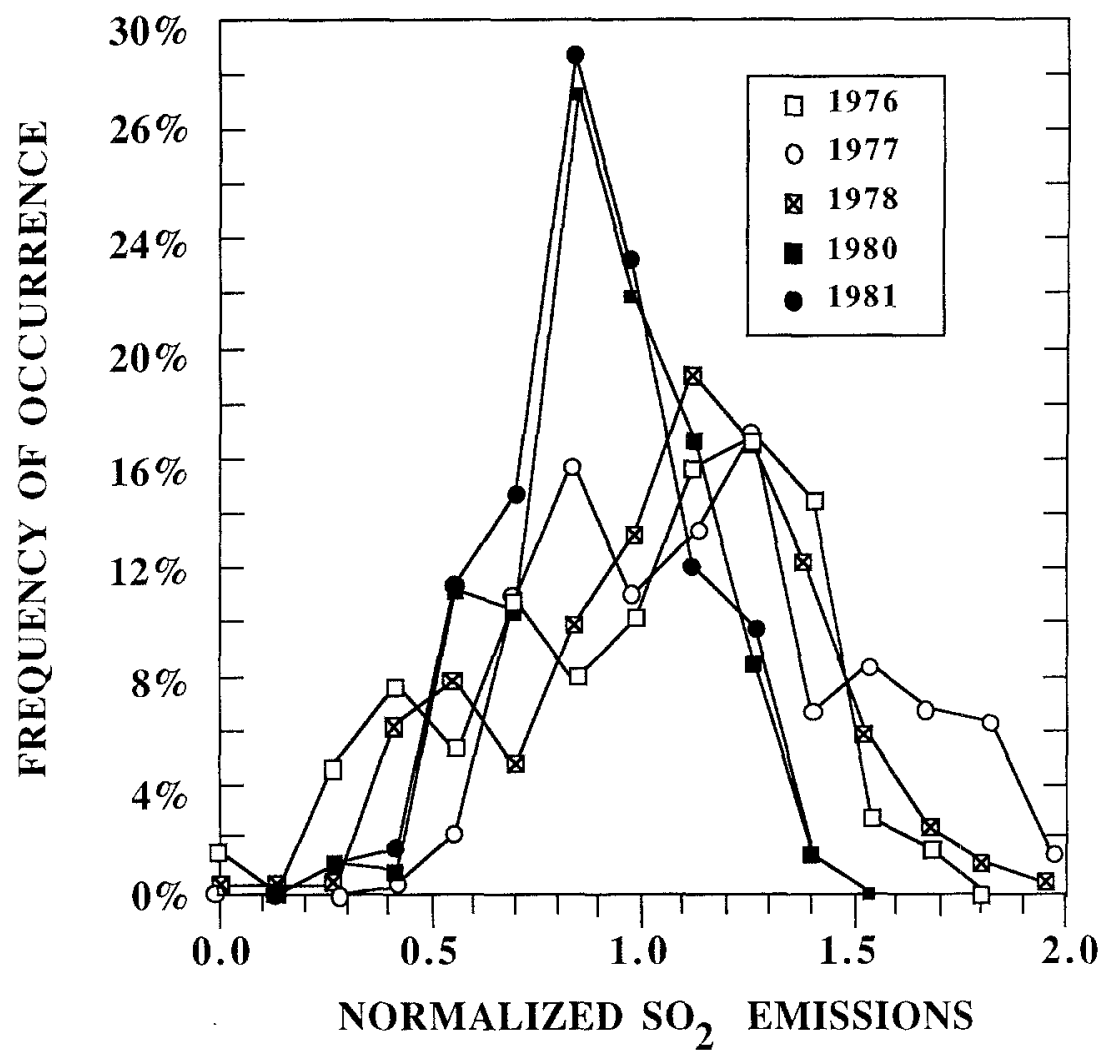

Figure 1. Frequency of occurrence of normalized $\mathrm{SO}_{2}$ emissions from a major electric generating facility for five separate years. Emissions are normalized by the mean emission rate for the five-year period. The distribution for 1981 is shaded for reference.

The constancy of emissions from this source in later years is seen by plotting the coefficient of variation (the standard deviation divided by the mean annual emission rate) as a function of averaging time in Figure 2. The plot shows that in general the standard deviation of daily emissions was about $30 \%$ of the mean when sampled on a daily basis but decreases with longer averaging to zero when the data were averaged over the whole year.

There were year-to-year variations in the pattern, with the 3 early years showing the highest variation relative to the mean and the later 2 years the least. The importance of using day-by-day emissions information is presumably increased for those years with the highest coefficient of variation. 


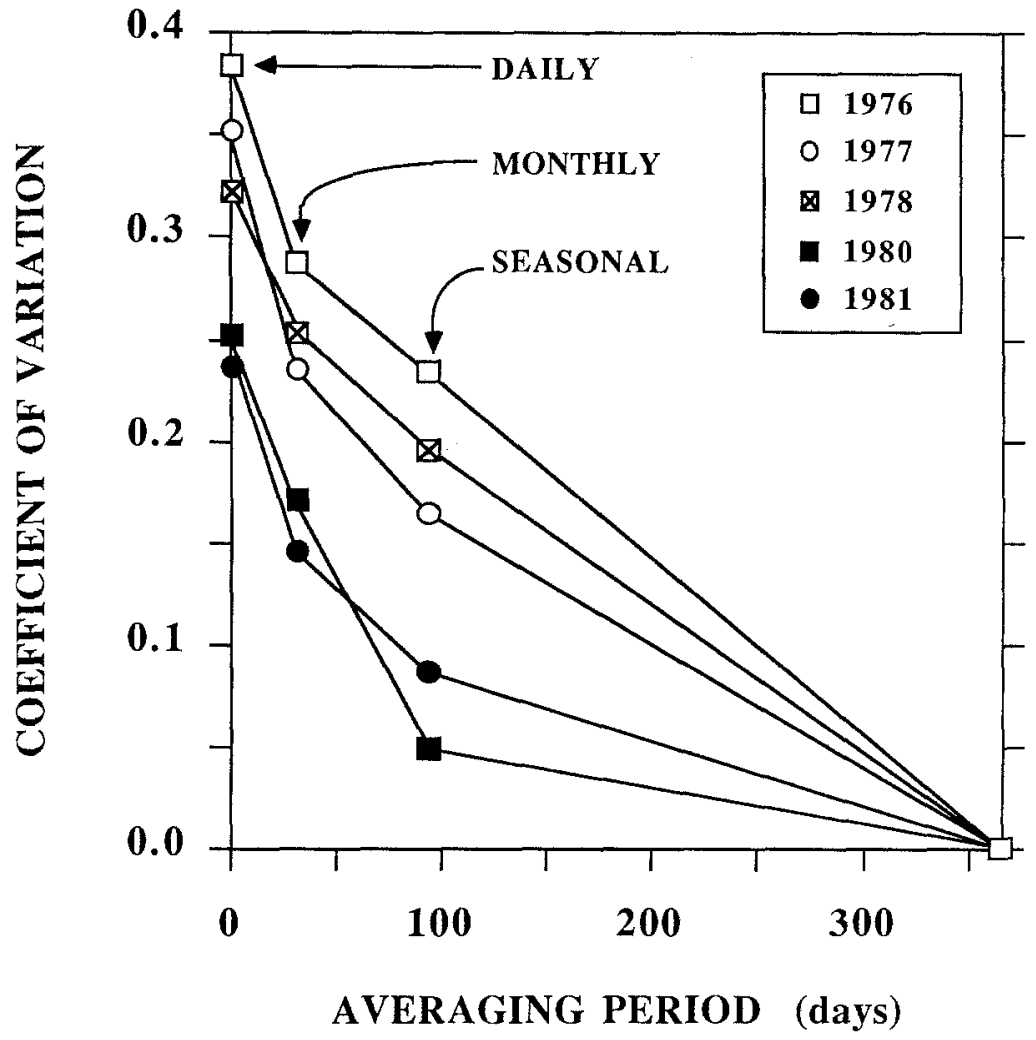

Figure 2. The coefficient of variation of $\mathrm{SO}_{2}$ emissions shown in Fig. I for five separate years.

Emissions data for all of the United States and Canada were used to model the interannual variations in deposition resulting from changing meteorological conditions. The data used in this study were obtained as part of the International Sulfur Deposition Model Evaluation (ISDME) study (Clark, 1985). These data represent point and area source emissions for 1980 .

\subsection{Meteorological Data}

The calculation of trajectories required the use of upper-air wind and temperature data. The data were obtained from the National Climatic Center in a format compatible with the NOAA-ATAD (Heffter, 1980) trajectory model. Precipitation information both at the receptors and upwind were derived from hourly precipitation data obtained from the National Climatic Center. These data were preprocessed to 
chronological files and then gridded into three-hour blocks as required by the ACID model. The gridding was based on ensemble averages of al1 reporting stations within each grid cell (see Keeler et al., 1984). The precipitation amount from the grids was joined with the calculated. trajectory location to provide an estimate of upwind pollutant removal.

\section{RESULTS}

\subsection{The Effect of Temporal Averaging of $\mathrm{SO}_{2}$ Emissions on Modeled Source-Receptor Relationships}

The results from model exercises using the daily, monthly and seasonally averaged emissions data were compared to the results from model runs using the annually averaged data to identify the level of uncertainty introduced into modeling estimates when sub-annual fluctuations in deposition were ignored.

The estimated spatial distribution of $S$ wet deposition potential. resulting from a single point source presumed located in the Detroit Metropolitan area in 1976 is shown in Figure 3. These calculations suggest that the area of maximum exposure to wet $s$ deposition extends to the east and north of this source region. The relatively long distances predicted between $\mathrm{SO}_{2}$ emission and $S$ wet deposition were presumably due to the slow conversion of $\mathrm{SO}_{2}$ to $\mathrm{SO}_{4}{ }^{2}$, the latter being more efficiently scavenged by precipitation than the former. The preference for the $S$ wet deposition potential to be highest to the northeast of the source was the result of the higher natural probability for southwest winds to be associated with precipitation.

The variability in estimated $S$ wet deposition potential due to the choice of temporal averaging period of input emissions can be demonstrated by plotting the percent difference fields of daily, monthly and seasonally averaged emissions results versus those of the annually averaged emissions.

Since the difference was generally greatest between the annual and the daily averaged emissions output and since 1976 was the year with the greatest variability in the emissions, the percent difference for $S$ wet deposition between the annually and daily averaged emissions results for 1976, shown in Figure 4, illustrates the expected worstcase variation.

The plot shows that $s$ wet deposition estimates exhibited an area of difference of greater than $20 \%$ in northeastern ohio and northern Pennsylvania. Another area of greater than $20 \%$ difference occurred in eastern Tennessee and Kentucky and western North Carolina, but the frequency of transport to these regions was estimated to be fairly low (Fig. 3) .

Thus, lack of detailed emissions information lead to variations in the spatial distribution of potential annual deposition of the order of only $20 \%$. However, the importance of using detailed emissions data will, presumably, increase with decreasing deposition averaging time. on the other hand, the variations in the emissions from an ensemble of sources within a grid cell (such as would be included in a regional- 


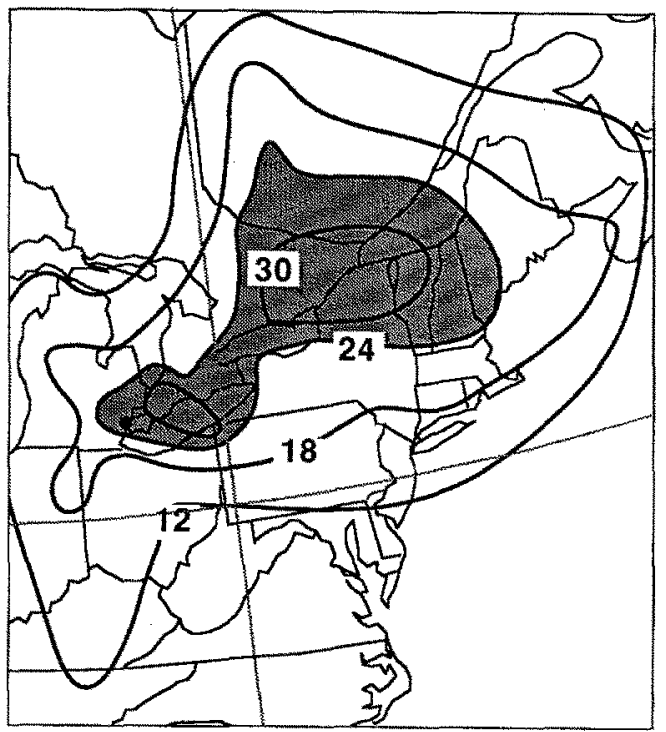

Figure 3. Probability of $S$ wet deposition from a source located in Southeastern Michigan using 1976 annual average emissions and 1976 meteorology. Units are $10^{-6}$ $\mathrm{km}^{-2}$.

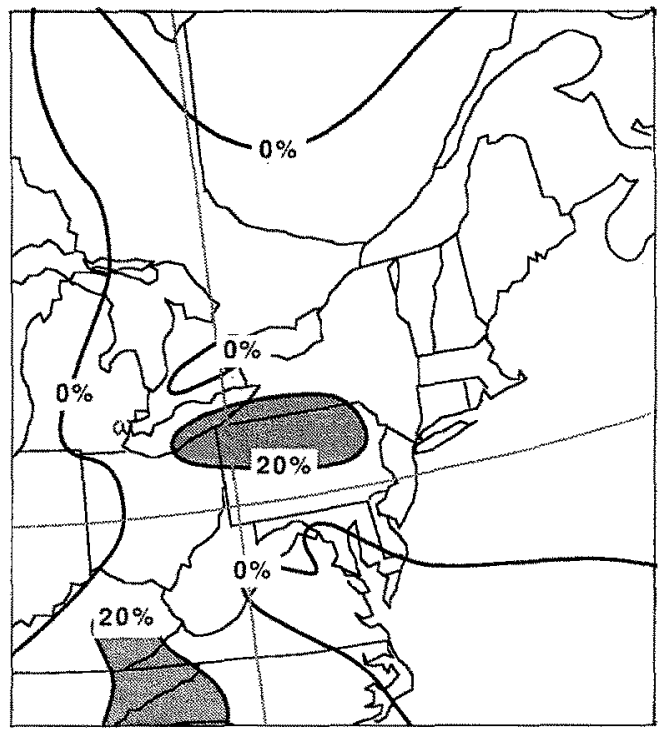

Figure 4. The percent difference between the probability of $S$ wet deposition calculated for a source in southeast Michigan using 1976 meteorological conditions and daily emissions values and that obtained using the annual average emission rate. 
scale transport and deposition model) would not be as pronounced as those for a single source.

\subsection{Variations in Estimated $S$ Wet Deposition in the Adirondacks due to Variations in Meteorological Conditions}

The variation of estimated ambient $\mathrm{SO}_{4}=$ concentrations and $S$ wet deposition due solely to variations in meteorological factors represents the "noise" upon which a signal of changing emissions is impressed. To evaluate the magnitude of this meteorological "noise", the ACID model was run in the backward mode for the ten receptors listed in Table I tor each of six years using fixed 1980 annual $\mathrm{SO}_{2}$ emissions. Figures 5 and 6 show the predicted annual average ambient $\mathrm{SO}_{4}=$ concentrations and $\mathrm{S}$ wet deposition, respectively, at each of the ten sites for each of the six years (1976-1981).

The range of predicted $\mathrm{SO}_{4}=$ concentrations were large at some sites and less at others. The variations in estimated annual average $\mathrm{SO}_{4}{ }^{=}$ concentrations had a range of variation of about $-20 \%$ to $+35 \%$ (ignoring Marcell, MN and Meade, NB where higher variations were predicted due to the low predicted values). The relative variation in ambient $\mathrm{SO}_{4}=$ was generally less than the relative range of the $S$ wet deposition as would be expected because of the added variability in precipitation timing. The estimated annual $S$ wet deposition varied about $-45 \%$ to $+45 \%$ from the deposition estimated for 1980. The range of predicted $S$ wet deposition was relatively large for some of the receptors including Caldwell, Ohio; Kane Experimental Forest, Pennsylvania; Parsons, West Virginia; and Dorset, Ontario. Thus the model predicts that large variations in $S$ wet deposition can be due to the variations in meteorology alone.

Table I. Receptor Site Locations for Multi-Year Modeling Analyses

$\begin{array}{lll}\text { Whiteface Mountain, New York } & 44^{\circ} 23^{\prime} & 73^{\circ} 35^{\prime} \\ \text { Kane Experimental Forest, Pennsylvania } & 41^{\circ} 36^{\prime} & 78^{\circ} 46^{\prime} \\ \text { Dorset, Ontario } & 45^{\circ} 13^{\prime} & 78^{\circ} 56^{\prime} \\ \text { Parsons, West Virginia } & 39^{\circ} 05^{\prime} & 79^{\circ} 40^{\prime} \\ \text { Hubbard Brook, New Hampshire } & 43^{\circ} 57^{\prime} & 71^{\circ} 42^{\prime} \\ \text { Georgia Station, Georgia } & 33^{\circ} 11^{\prime} & 84^{\circ} 24^{\prime} \\ \text { Marcell, Minnesota } & 47^{\circ} 32^{\prime} & 93^{\circ} 28^{\prime} \\ \text { Meade, New Brunswick } & 39^{\circ} 48^{\prime} & 81^{\circ} 32^{\prime} \\ \text { Caldwell, Ohio } & 39^{\circ} 48^{\prime} & 81^{\circ} 32^{\prime} \\ \text { Coweeta, North Carolina } & 35^{\circ} 04^{\prime} & 82^{\circ} 26^{\prime}\end{array}$




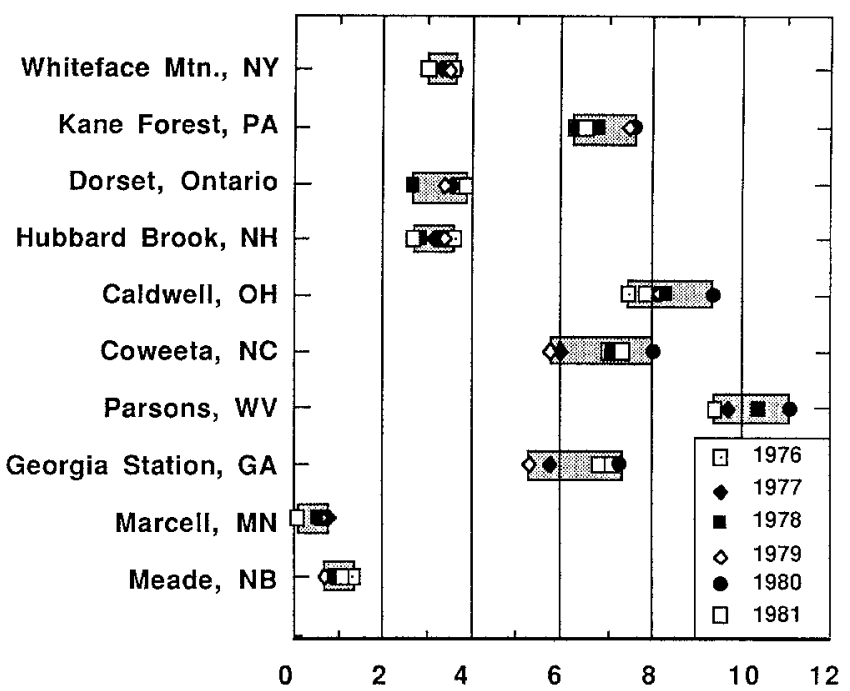

Predicted Annual Average $\mathrm{SO}_{4}=\left(\mu \mathrm{gm}^{-3}\right)$

Figure 5. The predicted annual ambient $\mathrm{SO}_{4}=$ concentrations for each of the sites listed in Table I for each of six years.

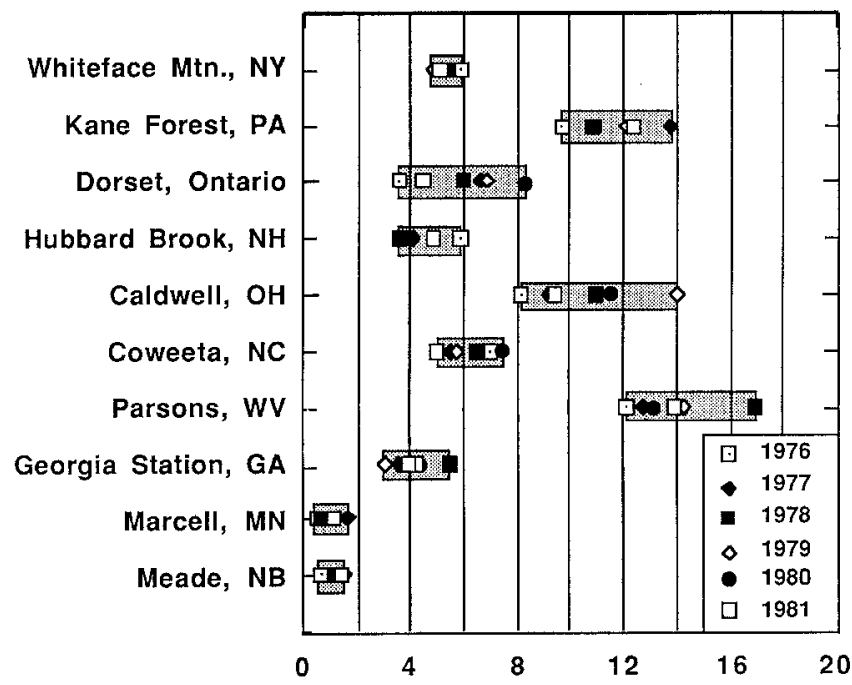

Predicted Annual S Deposition (kg/ha)

Figure 6. The predicted annual $S$ wet depositions for each of the sites listed in Table I for each of six years. 


\subsection{Variations in Estimated Source-Receptor Relationships Due to Variations in Meteorological Conditions}

The changing contributions of States and Provinces to annual average $\mathrm{SO}_{4}=$ concentrations and total annual $S$ wet deposition at one of the receptors have been estimated using the ACID model in the backward. mode. The changes in contribution reflect only the changing meteorological conditions from year-to-year.

Figure 7 shows the estimated absolute contribution of several states and/or Provinces to the annual average $\mathrm{SO}_{4}=$ concentrations at whiteface Mountain, New York for each of six years modeled. Predicted absolute contributions changed considerably from year-to-year. The estimate of

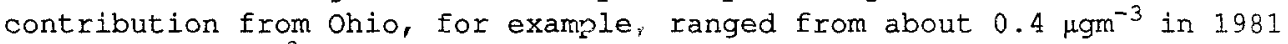
to over $0.6 \mathrm{\mu gm}^{-3}$ in 1979. Ontario, which was estimated to contribute the highest amount over the year was relatively stable in its contribution level. This variability could indicate the more episodic nature of transport from states in the Ohio River Basin.

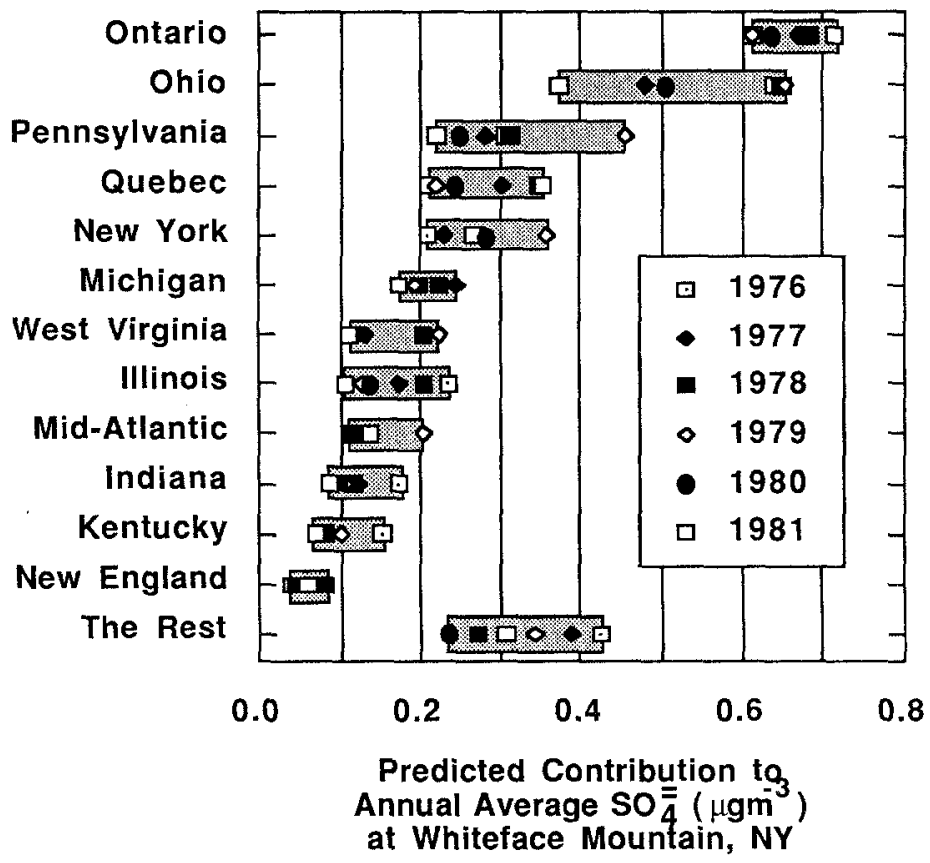

Figure 7. Variations in predicted contributions of various States and Provinces to annual ambient $\mathrm{SO}_{4}=$ concentrations at Whiteface Mountain, NY over a 6 -yr period. It is assumed that $\mathrm{SO}_{2}$ emissions for all years are equal to the 1980 emission rate, thus these numbers represent variations due to changing meteorological conditions only. 
Figure 8 contains the estimated absolute contribution of several States and/or Provinces to the annual total $S$ wet deposition at Whiteface Mountain, New York for each of the six years modeled. The figure shows that the predicted absolute contribution to $S$ wet deposition can also change considerably from year-to-year. The estimate of contribution from ohio ranged from about $0.9 \mathrm{~kg} \mathrm{ha}^{-1}$ of $S$ in 1979 to about $1.2 \mathrm{~kg} \mathrm{ha}^{-1}$ in 1980 . The increased importance of ohio and Pennsylvania sources for $S$ wet deposition reflect the bias in prevailing winds when precipitation occurred at the Whiteface Mountain site.

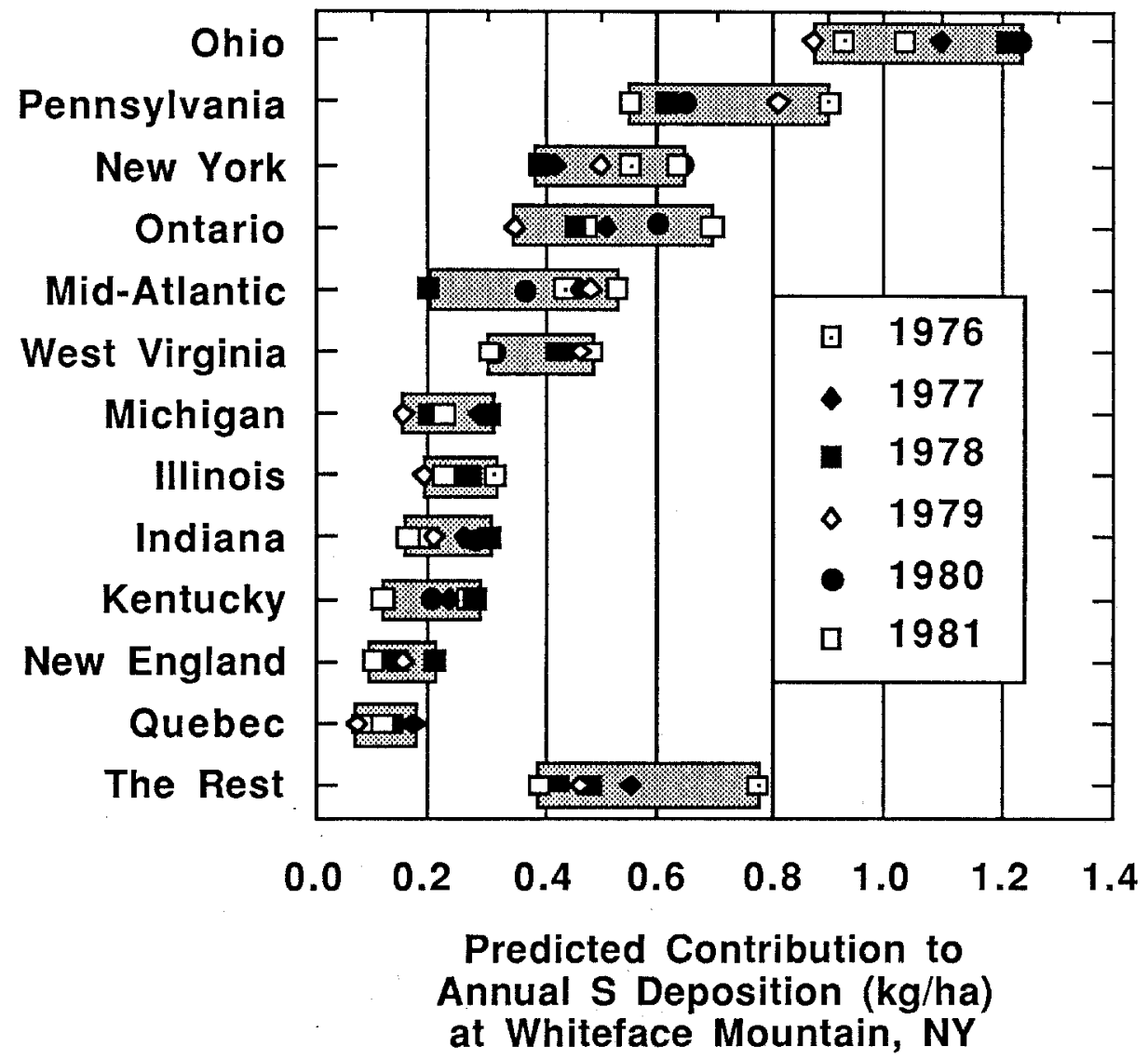

Figure 8. Variations in predicted contributions of various states and Provinces to $S$ wet deposition at Whiteface Mountain, NY over a 6 -yr period. It is assumed that $\mathrm{SO}_{2}$ emissions for all years are equal to the 1980 emission rate, thus these numbers represent variations due to changing meteorological conditions only. 


\section{SUMMARY AND CONCLUSIONS}

The failure to include sub-annual emissions variations in a Lagrangian regional-scale transport and deposition model with linear, first-order chemical conversion rates lead to variations in spatial patterns of source contributions of the order of $20 \%$ or less. While this variation is relatively small we have ignored possible non-linear interactions due to changing emissions of other pollutants such as nitrogen oxides and hydrocarbons.

Variations in meteorological conditions from year-to-year lead to variations in simulated $\mathrm{SO}_{4}{ }^{2}$ concentrations and $S$ deposition independent of the influence of changing emissions. Estimates of deposition over six years varied from $-20 \%$ to $+35 \%$ of the $\mathrm{SO}_{4}{ }^{2}$ simulated for 1980 . The variation in total annual $S$ wet deposition was roughly $\pm 45 \%$ of the amount simulated for 1980. The implication of these variations is that monitoring of trends in air concentrations and deposition due to changing emission values will need to be maintained for a sufficiently long time so that the trend could be discerned from the "noise" introduced by meteorology.

Similarly, the changes in simulated source-receptor relationships from year-to-year were substantial for certain state and Province source regions and the Whiteface Mountain location. The variations predicted suggest that the success of targeted emission control scenarios could be very difficult to evaluate.

\section{REFERENCES}

Clark, T.L.: 1985, private communication.

Heffter, J.L.: 1980, Air Resources Laboratories Atmospheric Transport and Dispersion Model (ARL-ATAD), NOAA Tech. Memo. ERL ARL-81, Air Resources Laboratories, Silver Springs, MD, $17 \mathrm{pp}$.

Keeler, G.J., Samson, P.J., and Small, M.J.: 1984, Representativeness of precipitation data in regional-scale acid deposition modeling, in The Meteorology of Acid Deposition, ed. P.J. Samson, Air Pollut. Cont. Assoc., Pittsburgh, PA, 225-240.

Samson, P.J. and Small, M.J.: 1984, Atmospheric trajectory models for diagnosing the sources of acid precipitation, in Modeling of Total Acid Precipitation Impacts, ed. J.I. Schnoor, Acid Precipitation Series, Vol. 9, Butterworth Publ., Boston, MA, $1-24$.

Scott, B.C.: 1982, Theoretical estimates of the scavenging coefficient for soluable aerosol particles as a function of precipitation type, rate and altitude, Atmos. Environ., 16, 1753-1762. 